\title{
Conceitos estoicos e hedonistas em jogos de linguagem: pathos em análise no guia do carro
}

\author{
Andréia Honório da Cunha
}

\section{Introdução}

\section{(...) representar uma linguagem equiva- le a representar uma forma de vida. ${ }^{1}$}

\begin{abstract}
proposta deste capítulo é discutir a utilização dos conceitos estoicos e hedoA nistas no discurso propagandístico veiculado pelo guia dos carros no site de notícias Terra em 19 de junho de 2020, e como esses conceitos se materializam em jogos de linguagem, conforme Wittgenstein, ao variarem seus sentidos no corpus em análise. Pressupomos que esse jogo facilita a manifestação do pathos em favor do produto pelas vias da escolha de argumentos quase-lógicos bem como de argumentos que priorizam o valor da quantidade-qualidade. Para tanto, nossas questões problematizadoras são: i. Como os conceitos filosóficos do estoicismo e do hedonismo se relacionam com os jogos de linguagem propostos por Wittgenstein no discurso propagandístico? ii. Como o pathos se manifesta nesse discurso de forma a mobilizar o auditório para o produto anunciado?

Nosso percurso de escrita inicia-se com a contextualização histórica tanto da doutrina estoica quanto hedonista e suas respectivas teses. Discorreremos sobre as questões problematizadoras e os principais conceitos abordados por ambas. Em seguida, abordamos a ascensão da filosofia analítica da linguagem com Ludwig Wittgenstein (1889-1951) em duas obras: tractatus philosophicus e investigações filosóficas com a conjectura dos conceitos de formas de vida e
\end{abstract}

Wittgenstein, 1996, p. 19 
jogos de linguagem. Nos aspectos teóricos, nossa discussão adentrará os aspectos publicitários defendidos por Meyer (2018) e a argumentação quase-lógica e pelo valor da quantidade-qualidade sob a perspectiva de Perelman e Olbrechts-Tyteca (2005[1958]) e a noção de pathos em Galinari (2014).

Intentamos, com esse percurso, demonstrar como as conceituações de forma de vida e jogos de linguagem se presentificam no corpus selecionado por meio das argumentações e colaboram para a manifestação do pathos visto como chave ou ferramenta de leitura sob a perspectiva retórica-discursiva, conforme Galinari (2014). Terminamos com as considerações finais ante os resultados obtidos seguidos das referências bibliográficas utilizadas para a realização deste estudo.

\section{O pensamento helenístico e suas doutrinas: o estoicismo e o hedonismo}

Compreendido entre os séculos III e II a.C., sob a influência do império macedônico, o período helenístico é marcado pelo surgimento de duas doutrinas filosóficas: o estoicismo com Zenão de Cítio (333 a.C-263 a.C.) e o hedonismo com Epicuro (341-270 a.C.). Ambas adotam como questão problematizadora qual seria o melhor critério condutor do comportamento humano.

Todavia, em suas teses, evidenciam-se perspectivas diferenciadas que as tornaram antagônicas em suas concepções. "Zenão de Cítio via o mundo como racionalmente ordenado e afirmava que a paz de espírito é alcançada mediante $o$ controle das paixões". ${ }^{2}$ A doutrina estoica compreende, portanto, que o homem deve ser guiado pela razão, pois é nela que reside a natureza humana. As paixões intensas devem ser evitadas, visto encobrirem a real natureza humana.

Para Epicuro, a filosofia é o fármaco mais indicado para as três patologias mais frequentes: o medo dos deuses, da morte e da dor. Materialista e atomista, o filósofo crê na finitude da vida com a morte, por isso, sua doutrina "oferece como remédio a busca de um sadio e moderado prazer de viver"3 $\mathrm{e} o$ adota junto à busca pela felicidade como critérios condutores do humano.

Para tanto, desdobra o problema na busca pela definição de qual seria o verdadeiro prazer e como lidar com o prazer imediato e a dor. A razão adentraria não como a natureza humana per se, mas como instrumento moderador das necessidades humanas, tais como eliminação do medo, que implica dor, na

2 Law, 2011, p. 252

3 Nicola, 2011, p. 106 
Conceitos estoicos e hedonistas em jogos de

moderação do gozo/prazer que se estabelece como meta da busca pela tranquilidade de espírito e a serenidade. A razão no estoicismo é considerada elemento controlador das paixões intensas, já no hedonismo ela é o fio que desemaranha as relações das paixões que causam dor e prazer tendo em vista o equilíbrio: a felicidade almejada pelo humano.

A compreensão do desejo no estoicismo está na impassibilidade - no controle do racional sobre o emocional que perturba o indivíduo. A indiferença é a qualidade do sábio, bem como a apatia - apathea -, na supressão dos desejos em busca da serenidade. O homem não deve ser escravo da racionalidade, mas seguir o ideal de uma moderada razoabilidade. ${ }^{4}$

No hedonismo, há a distinção entre os desejos naturais e desejos inúteis. O desejo natural provém ou de uma necessidade, um desejo natural necessário - livrar o corpo da fome, da sede, da dor, etc. -; ou de um desejo natural não necessário: variar comidas, bebidas, o prazer do corpo, por exemplo. Há também o desejo não natural e não necessário, visto como os que nascem de uma opinião falsa sobre o mundo incentivada por vaidade, orgulho, inveja, etc.

$\mathrm{Na}$ concepção de Epicuro, um dos maiores prazeres era o intelectual: filosofar entre amigos, por exemplo. A seu ver, a busca por prazeres momentâneos implicava a não garantia de um bem-estar a longo prazo. Dessa forma, "o objetivo [do hedonismo] é o equilíbrio em vez de extremos de prazer, que levam inevitavelmente à dor". ${ }^{5}$

Sob o ponto de vista do senso comum, para os estoicos, a vida virtuosa está em harmonia com a ordem natural racionalmente ordenada pelo legislador divino. A aceitação humana com o que não se pode mudar, aliada à apatia, caracteriza a ideia de estoicismo na imaginação popular. Já no hedonismo caricaturado a maximização da busca pela felicidade deve ser a meta da vida. Detratores da doutrina, por isso, pregam uma busca desenfreada por prazeres vis, sem que, de fato, essa seja a meta original divulgada por Epicuro.

\section{Wittgenstein: do tractatus às investigações de jogos de linguagem}

As concepções de Ludwig Wittgenstein alçam notoriedade científica no contexto da virada linguística, décadas finais do século XX, sobretudo por

Ibid., p. 115

Law, 2011, p. 251 
contribuir com a filosofia analítica da linguagem. Por ser dinâmico em seus pensamentos e considerar que seu primeiro estudo falha na compreensão da linguagem, o filósofo é retratado em seu antes e depois por meio de suas obras: o Tractatus Philosophicus (1921) e as Investigações filosóficas (1953).

A convicção de Wittgenstein, no Tractatus Philosophicus, estrutura-se na lógica e na metafísica como instrumentos de análise do discurso factual. A tese desse período declara que os fundamentos da linguagem têm intima ligação com os fundamentos do mundo, haja vista, o mundo nos ser dado independente da linguagem, mas a linguagem ter por função o exprimir. ${ }^{6}$

Os alicerces desse pensamento respaldam-se na filosofia designativa de Platão para a qual cada significado corresponde à denotação de apenas um objeto. Dessa forma, a metáfora da caixa de ferramentas encaixa-se com uma concepção atomista como meio de elucidação da linguagem considerada instrumento de representação do mundo.

Ao longo de seu percurso investigativo, todavia, Wittgenstein reconhece que sua teoria inicial estava orientada mais para uma função descritiva e, por isso, não dava conta de explicar todos os usos da linguagem, principalmente o relativo às fronteiras internas do exame da significação. Dessa forma, o filósofo dá continuidade as suas Investigações Filosóficas, obra publicada postumamente.

A tese desse trabalho rompe com a primeira, pois declara que o significado de uma expressão é o uso que se pode fazer dela nos vários jogos que constituem a linguagem. ${ }^{7}$ A filosofia wittgensteiniana do segundo momento preconiza o uso da linguagem a três condições: i. ao uso de regras para a condição de como as palavras são utilizadas; ii. à observação do contexto empregado nas palavras, definido como jogos de linguagem ${ }^{8} \mathrm{e}$ iii. às funções que as palavras devem desempenhar, conceituado como formas de vida. ${ }^{9}$

A conceituação de regras vincula-se à práxis ${ }^{10}$ comunicativa interpessoal socialmente contextualizada por padrões de correção, visto ser impossível seguir

6 Júnior, 2011, p. 74

7 Ibid

8 Conceito considerado como de primeira ordem por Wittgenstein (1996) visto abarcar outros conceitos em si. Os jogos de linguagem se constituem da unidade entre o uso e a língua, a práxis e a interpretação de uma situação, por fim o conceito torna-se relevante pois por ele temos a relação com uma linguagem imediata do dia-a-dia. $\mathrm{O}$ autor recusa-se a dar uma definição precisa do que seja jogos de linguagem visto incorrer em essencialismo

9 Conceito utilizado por Wittgenstein considerado de segunda ordem que sustenta uma conduta comum da humanidade numa base constituída por uma concordância coletiva em reações primitivas, o que equivale a dizer em tipos de condutas pré-linguísticas, segundo Valle (2003). Essa conduta serve para representar todas as atividades comuns à humanidade tais como a poética, a filosofia, a política, o comércio, etc. Fonte: $<$ https://revistas.ufrj.br/index.php/Itaca/article/view/226/215 > acesso em 05 de julho de 2020 às 17 h06min

10 Definição utilizada no sentido teleológico proposto por Marx - união dialética entre teoria e prática na obtenção de um fim consciente ao humano 
Conceitos estoicos e hedonistas em jogos de

uma regra privadamente. ${ }^{11}$ A práxis, por sua vez, demanda novos usos e confere compreensão, correção e sucesso às regras por sua aplicação.

As formas de vida conferem, por meio do uso, o exame da significação das palavras e como elas se manifestam no contexto. O cerne das formas de vida está na interação das ações humanas pelas vias da linguagem. O conteúdo psicológico da palavra é visto como algo vivencial que lhe confere um caráter pessoal vinculado a atos não acessíveis somente pela observação.

Portanto, as formas de vida requerem técnica no saber jogar com a linguagem, pois são elas que delimitam a clareza da expressão linguística. As noções formas de vida, regras e jogos de linguagem não são claramente definidas pelo autor, no entanto, Wittgenstein indica que é necessário "ver a frase como instrumento, e o seu sentido como emprego" ${ }^{12}$

Essa mudança de paradigma no pensar filosófico sobre a linguagem rompe com a semântica tradicional e permite a recriação de uma estrutura lógica do mundo construída com base na interpretação de dados recebidos a partir da vivência nas quais os objetos estão dependentes da complementação com significados adquiridos numa proposição linguística.

\section{As categorias analíticas}

A eficácia dos discursos depende da utilização das formas simbólicas na busca por objetivos a serem alcançados. Esta assertiva evidencia característica primordial dos discursos propagandísticos: a validação das informações por meio dos saberes como recurso à sedução.

Os saberes estão vinculados ao saber saber, caráter do ethos; ao saber fazer, logos e ao fazer sentir, pathos. No âmbito do saber saber, a busca pela identidade do interlocutor almejado torna-se um problema retórico, pois é nesse espaço que ocorre a anulação das diferenças, a aproximação do sujeito ao objeto e as ilusões seja de afastamento seja de comunhão que levam os homens a agirem em comum para o melhor ou para o pior. ${ }^{13}$ Nessa construção, o saber fazer implica na escolha de argumentos, pois são eles que garantem a adesão em maior ou menor nível do interlocutor ao que lhe é proposto como objeto de desejo.

No corpus selecionado, verificamos a presença da argumentação quase-lógica. De acordo com Ferreira, os argumentos quase-lógicos "são aqueles que se apresentam explicitamente e têm força persuasiva na proximidade (semelhança)

\footnotetext{
11 Wittgenstein, 1996, p. 202

12 Ibid., p. 421

13 Meyer, 2018, p. 136
} 
com argumentos formais". 14 A aparência lógica desses argumentos permite refutações, pois não fazem apelo à experiência, mas a demonstração. Em Perelman e Olbrechts-Tyteca, o desmascaramento dessa quase logicidade está "em pôr em evidência (...) o esquema formal que serve de molde à construção do argumento" seguido "das operações de redução"15 que visam tornar o esquema comparável, semelhante ou homogêneo.

$\mathrm{O}$ fazer sentir vincula-se à sedução pelas vias do pathos. Ainda em Meyer temos que "a sedução tem por objeto uma diferença para atingir a identidade, para tal cristaliza a aparência na qual o sujeito pode refugiar-se" ${ }^{16} \mathrm{O}$ eu esvaziado é preenchido pela aparência oca que a si se basta: o jogo da identidade tropológica.

Esse jogo instaura-se pelo imaginário, espaço no qual a sedução torna-nos sensíveis nos nossos desejos mais íntimos "metaforizados"17 e deslocados para essas aparências ocas. Entretanto, esse também não deixa de ser um jogo linguístico sistematizado na inventio como corresponde ao corpus em questão. Haja vista as comparações que fundem sujeito a objeto: carro-pessoa-cirurgia de rejuvenescimento. É pelo imaginário que o pathos se manifesta discursivamente seduz e mobiliza o leitor - no caso do corpus, para uma segunda chance para o Renault Duster. A visão analítica do pathos remonta a concepção de Galinari (2014).

$\mathrm{O}$ autor não apenas a concebe como prova retórica atrelada a ethos e logos. Ele a expõe numa perspectiva da Análise do Discurso como parte integrante da "dimensão discursiva" na condição "de chave ou ferramenta de leitura" que tem "efeitos possíveis" no plano da adesão. ${ }^{18}$

\section{O corpus em análise}

\section{RENAULT DUSTER É MAIS SUV DO QUE OS CARROS DA MODA}

Além de superar Chevrolet Tracker, VW T-Cross e Renault Captur nos atributos de SUV, Duster é maior, mais espaçoso, mais largo e mais barato.

Sergio Quintanilha

19 jun2020 - $12 \mathrm{~h} 25$

\footnotetext{
14 Ferreira, 2015, p. 149

15 Perelman; Olbrechts-Tyteca, 2005, p. 219

16 Meyer, 2018, p. 142

17 idem

18 Galinari, 2014, p. 257-8
} 
Conceitos estoicos e hedonistas em jogos de

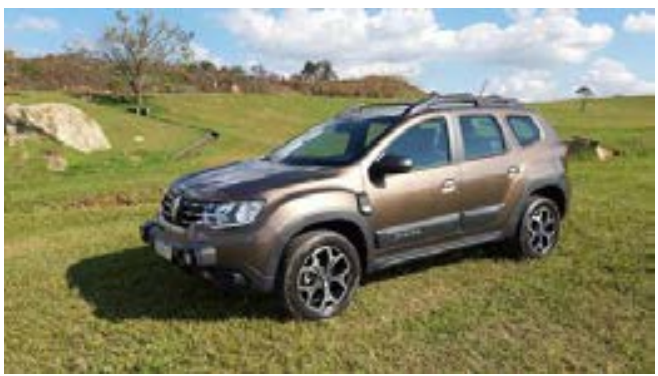

Renault Duster bate facilmente seus rivais diretos nos atributos off-road. Foto: Sergio Quintanilha / Guia do Carro

Parem de olhar para o Renault Duster com preconceito. O carro é bom. Ele passou por uma profunda cirurgia este ano e ficou muito mais confortável, tanto para os passageiros quanto para o motorista. Dirigir o Duster não é mais uma experiência estóica. Qualidades off-road ele sempre teve, mas era meio bruto, um tanto rude na entrega de prazer ao motorista. Agora, não. O novo Duster 2021 manteve suas características de robustez e ficou muito mais dócil.

Vivemos de comparações e o Duster sofreu com isso. Sua ascendência romena já é suficiente para entortar alguns narizes. Entretanto, a Renault não se limitou a fazer uma cirurgia plástica no Duster. Ela mexeu profundamente em questões de conforto, conveniência, praticidade e conectividade. O Duster 2021 ficou realmente diferente, tanto melhor quanto mais equipada é a versão que você escolhe.

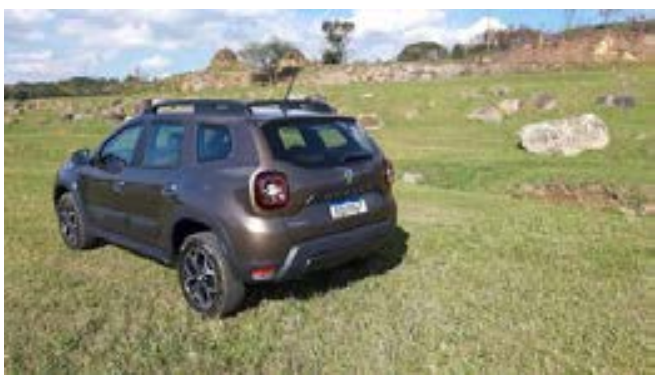

Essa graminha só apareceu na foto por causa das pedras: o Duster vai muito além disso.

Foto: Sergio Quintanilha / Guia do Carro

Mas até o conceito de caro é diferente no Duster. A versão topo de linha, Iconic, custa R\$90.690. O Duster Iconic 1.6 CVT é mais em conta do que o 
Chevrolet Tracker 1.0 LT (R $\$ 93.490)$, mais acessível do que o Renault Captur Intense 1.6 ( $\mathrm{R} \$ 97.690)$ e muito mais barato do que o Volkswagen T-Cross Comfortline 1.0 ( $\mathrm{R} \$ 110.260)$. A vantagem do Tracker e do T-Cross aparece no desempenho e em algumas medições de consumo, pois usam motor turbo. Mas o Duster tem seus trunfos.

Em relação a esses três SUVs, que são carros da moda, o Renault Duster é maior, mais largo, mais alto, mais espaçoso, transporta mais carga, leva mais bagagem, tem maior distância do solo e dá um banho nos ângulos de entrada, de saída e de transposição de rampa. O Duster é um SUV de verdade -- e isso não é novidade. Mas não custa repetir, pois o mainstream da moda às vezes leva todos os consumidores para um lado e alguns bons carros ficam esquecidos.

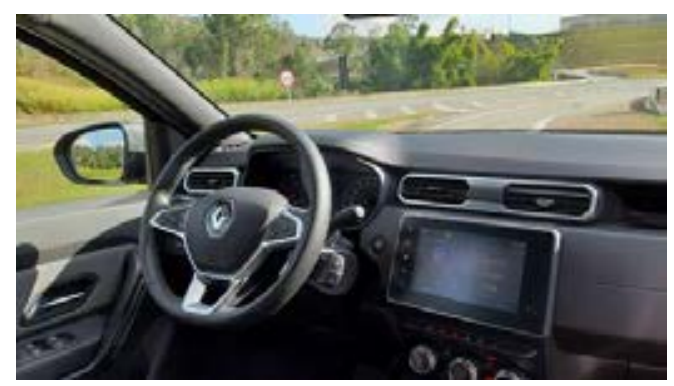

\section{Interior do Duster 2021 deu muito mais dignidade ao carro em termos de conforto.}

Foto: Sergio Quintanilha / Guia do Carro

Tem mais. O Duster ganha do Captur 1.6 e do T-Cross 1.0 no consumo urbano com gasolina. Perde para o Tracker 1.0. Na estrada, aí sim, perde para todos. Sua potência $(118 / 120 \mathrm{cv}$ com gasolina/etanol) é superior à do Tracker $(116 \mathrm{cv})$ e compatível com a do T-Cross $(116 / 128 \mathrm{cv})$ quando se compara a entrega com gasolina. De qualquer forma, apesar de surpreender e ganhar no consumo urbano com gasolina, essa não é a praia do Duster. Tampouco as provas de aceleração. Seu trunfo está mesmo no custo-benefício.

O problema (sério) do Duster era a falta de conforto. Era. Esse problema ele não tem mais. Painel, volante, bancos e central multimídia são novos. A nova central multimídia é a Easy Link, diferente da Media Nav usada nos demais carros da Renault. A tela tátil agora é de 8" e ficou posicionada mais acima do painel, o que melhorou sua observação durante a condução. 
Conceitos estoicos e hedonistas em jogos de

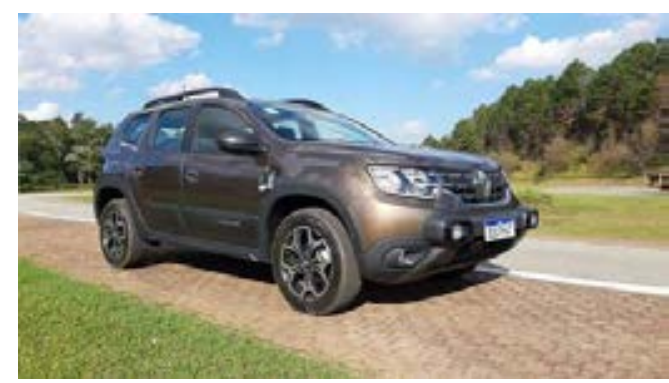

Renault Duster Iconic, topo de linha, custa R $\$ 90.690$.

Foto: Sergio Quintanilha / Guia do Carro

Poderia ser melhor se estivesse no mesmo nível de altura do quadro de instrumentos, mas já foi um avanço e tanto perante a telinha anterior. A vida a bordo do novo Duster é realmente mais agradável. Os bancos de couro e o redesenho do painel deixaram o carro com um nível de conforto igual ao de qualquer outro rival do segmento de SUVs compactos. Até na rigidez torcional da carroceria a Renault mexeu, aumentando-a em $12,5 \%$. As suspensões foram recalibradas, tornando o rodar mais confortável, e a assistência da direção agora é elétrica. O esforço para manobras diminuiu bastante.

O console central também foi completamente modificado, com novas saídas de ar. O sistema de ar-condicionado digital tem anéis cromados com oito velocidades e 19 opções de temperatura entre $17,5^{\circ} \mathrm{C}$ e $26,5^{\circ} \mathrm{C}$. Os painéis das portas ganharam apoio de braço revestido em tecido, novos puxadores e iluminação interna. O Duster 2021 oferece 1,5 litro a mais de espaço para porta-objetos do que o modelo anterior, atingindo 20,3 litros no total. Em resumo, a praticidade a bordo é um fato.

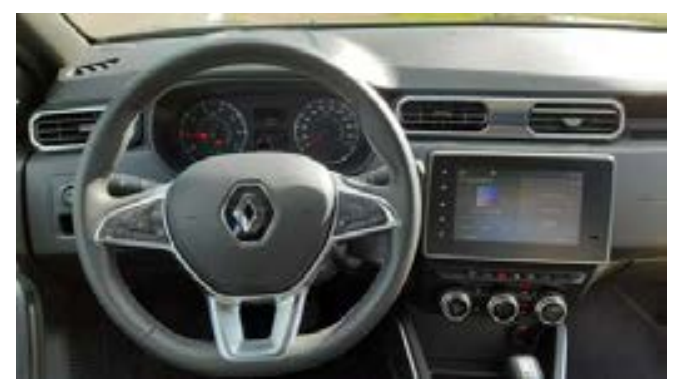

Volante de direção com boa pegada e nova tela multimídia mais ampla. Foto: Sergio Quintanilha / Guia do Carro

Outra novidade do Duster Iconic é o sistema Multiview, com quatro câmeras. A imagem aparece no novo display central. A câmera frontal, na parte de baixo do carro, ajuda a passar por lombadas íngremes, enquanto as câmeras 
laterais ajudam em trechos bem estreitos. Ele tem também uma câmera traseira, mais isso muitos carros têm. No segmento, o Renault romeno tem os maiores ângulos de entrada $\left(30^{\circ}\right)$ e de saída $\left(34,5^{\circ}\right)$ e a maior altura do solo $(237 \mathrm{~mm})$. Por isso, encara obstáculos com facilidade. O ângulo de transposição de rampa é de $22^{\circ}$. Além disso, ele mantém o maior porta-malas da categoria (475 litros).

Apesar dessas melhorias, a Renault ainda não teve tempo de estrear o novo motor 1.3 turbo. Nesse caso, não podemos culpar os consumidores mais exigentes nesse quesito. Nosso ponto aqui é com aqueles que olham com preconceito para o design e para o conforto do Duster. Que a Renault não cometa o erro de trazer o novo motor somente para o Captur, quando isso ocorrer.

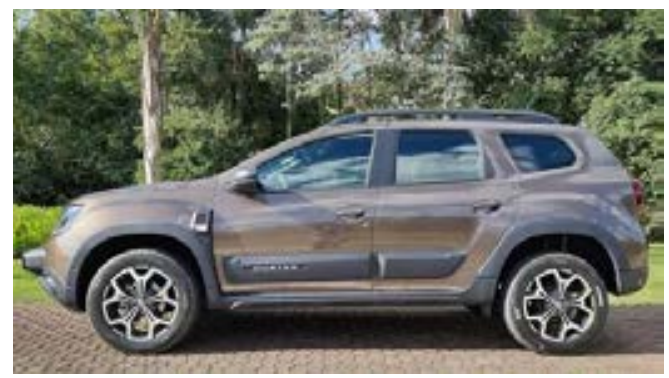

Duster é maior, mais largo, mais alto, mais espaçoso e mais prático do que os SUVs da moda.

Foto: Sergio Quintanilha / Guia do Carro

Rodamos na cidade e na estrada com o novo Duster Iconic 1.6 CVT. Ele não é uma referência em desempenho, mas ainda assim mostrou boa desenvoltura nas retomadas de velocidade. Mérito da engenharia da Renault, que encontrou boas relações de marcha para o câmbio CVT X-Tronic, que faz trocas automáticas sem intervenção do motorista e também permite antecipar uma ou duas marchas por meio da alavanca. A redução do nível de ruído a bordo também causou boa impressão durante nossa avaliação.

No geral, o novo Renault Duster mostra ser um carro rejuvenescido, com um posicionamento bem interessante no mercado, por isso suas vendas melhoraram. Ele já engoliu o Captur, deixou o Citroën Cactus e o Peugeot 2008 comendo poeira, ultrapassou o Ford EcoSport e se aproxima do Nissan Kicks. O novo Renault Duster 2021 é vendido em três versões: Zen ( $R$ \$ 74.690), Intense $(\mathrm{R} \$ 86.690)$ e Iconic ( $\mathrm{R} \$ 90.690)$.

$\mathrm{O}$ argumento do primeiro parágrafo do corpus alça sua força de convicção na demonstração do objeto em seu antes e depois. A definição e a identidade 
Conceitos estoicos e hedonistas em jogos de

do produto - o carro (Duster) é bom - são reduzidas a uma natureza nãoformal relativa ao suposto preconceito dos interlocutores para com o carro em contraposição à comparação com o estoicismo enunciada pelo produtor: Dirigir o Duster não é mais uma experiência estoica. Essa redução se resume na contradição e possível incompatibilidade das ideias: o que há no estoicismo que pode ser comparado a experiência de dirigir o Renault Duster? O que seria uma experiência estoica nesse caso? Notamos que o adjetivo estoica assume caráter negativo na interligação do jogo de ideias proposto no discurso. Todavia, que mal há em aderir à razão como critério condutor do humano pela não aderência às paixões intensas - tese defendida pelos estoicos?

De acordo com Wittgenstein, a linguagem está atrelada a formas de vidano caso do corpus em análise, a do produtor dessa comparação. Todavia, esta se contextualiza dentro de uma relação comunicativa interacional não desprovida de intencionalidade, haja vista tratar-se de uma análise de cunho propagandístico. Nesse caso, experiência estoica está para meio bruto e um tanto rude em contraposição ao na entrega de prazer ao motorista e a docilidade expressa pelo enunciado ficou muito mais dócil.

A implicitude do hedonismo em oposição à explicitude do estoicismo denota obscurecimento da incompatibilidade dos argumentos ante a evidência de ambos os elementos comparativos. A explicitude de ambos incorreria no "trazer a lume a incoerência de um conjunto de proposições" que corresponde a "expô-lo a uma condenação inapelável". ${ }^{19}$ Dessa forma, embora implícito em sua denominação, o hedonismo está evidente em todas as qualidades que remetem ao conceito de prazer ao motorista ao objetivarem, por exemplo, o conforto e as novidades como finalidades para a lógica da sedução do interlocutor. Os argumentos que apelam ao valor da quantidade-qualidade se aliam na demonstração desse artificio: o Renault Duster é maior, mais largo, mais alto, mais espaçoso, transporta mais carga... é um SUV de verdade - e isso não é novidade.

A relação da obtenção prazer, consequentemente, fundamenta-se nessa argumentação quase-lógica. A incompatibilidade das ideias no plano argumentativo quase-lógico ao relacionar estoicismo com experiência estoica para dirigir um carro, porém aceitação por parte dos interlocutores está na redução concluída como definição que aparenta clareza enredada numa "trama subjacente" ${ }^{20}$ - na qual o hedonismo é o elemento que subjaz a argumentação na materialização do prazer a instrumento de comparação antagônica, assim como ocorria com as duas doutrinas no período helenístico.

19 Perelman; Olbrechts-Tyteca, 2005, p. 221

20 Ibid., p. 220 
A distinção no plano discursivo entre o que é estoico e o que é hedonista (implícito) ocorre por meio das proposições adversativas. Assim temos: a ascendência romena suficiente para entortar narizes a característica estoica seguida de entretanto para a apresentação das questões de conforto, conveniência, praticidade e conectividade como características que acentuam o prazer ao motorista; bem como na evidência da diferença do conceito de caro textualmente marcada com o mas ao objetivar os valores de qualidade: maior acessibilidade - mais acessível -, melhor preço, melhor desempenho pela utilização de motor turbo como trunfos a serem evidenciados.

A escolha pelos advérbios de modo facilmente e profundamente modificam a relação dos verbos bater e mexer - bate e mexeu - com intentos de trazer veracidade às mudanças ocorridas no Duster. Há ainda as combinações de advérbios com adjetivos: realmente diferente, completamente modificado utilizados como recursos que acentuam as qualidades realçadas com a fama de forte e resistente no uso do diminutivo graminha seguido do enunciado: o Duster vai muito além disso.

O pathos, portanto, se presentifica no discurso tanto pela escolha da argumentação que apela para os valores quantidade-qualidade bem como pelo imaginário que apela pela sedução para aquilo que se considera como o ideal de conforto para o leitor alçado a identidade de motorista. E a alterna ao comparar o objeto como pessoa que passa por cirurgia de rejuvenescimento ao demonstrar a boa impressão que a Renault executou nas modificações do novo modelo 2021 para o carro.

O desmascaramento da argumentação quase-lógica está na redução do esquema formal conforme proposto por Perelman e Olbrechts-Tyteca. Assim, temos:

\author{
Esquema formal: \\ Premissa maior - Todo carro SUV é bom. \\ Premissa menor - O Duster é um SUV. \\ Conclusão - Logo, o Duster é bom.
}

Já o esquema da argumentação quase-lógica parte da relação de comparação Renault Duster antes um carro estoico, Renault Duster depois; mais SUV que outros.

Esquema quase-lógico:

Premissa maior - Todo carro SUV é bom.

Premissa menor - O Duster (atual) é mais SUV que os carros da moda. 
Conceitos estoicos e hedonistas em jogos de

Conclusão - Logo, o Duster é o melhor dos SUV do que os demais carros (SUV) da moda.

\section{Considerações finais}

Verificamos pela análise que os conceitos do estoicismo e do hedonismo foram alçados no discurso propagandístico para evidenciar o antes e o depois do produto anunciado. As relações com os jogos de linguagem se estabelecem por meio da atribuição de sentidos sendo estes: experiência estoica com sentido negativo que remete a meio bruto, um tanto rude em contraposição à entrega de prazer ao motorista com a substantivação robustez e adjetivação para ficou muito mais dócil dentre outras características positivas acentuadas pela argumentação que apela para os valores quantidade e qualidade.

O pathos se manifesta discursivamente pela argumentação quase-lógica por comparação. A identidade tropológica atribuída ao leitor é do sujeito que anseia "dignidade" para uma experiência "em termos de conforto" com um novo carro - no caso o Renault Duster 2021. São os atributos ressignificados tanto pela comparação estoicismo/hedonismo via escolhas lexicais e argumentação quase-lógica quanto pela relação "sujeito-carro-cirurgia de rejuvenescimento" que seduzem o leitor para a aquisição do produto e o fazem crer que o Renault Duster é mais SUV do que os carros da moda.

\section{Referências}

FERREIRA, L. A. Leitura epersuasão: princípios da análise retórica. São Paulo: Contexto, 2015.

GALINARI, M. M. Logos, ethos e pathos: "três lados" da mesma moeda. IN: Alfa, São Paulo, 58 (2): 257-285, 2014. < http://dx.doi.org/10.1590/1981-5794-1405-1 >

JÚNIOR, L.P. O conceito de lebensform (formas de vida) na filosofia de Wittgenstein. IN. Ítaca. Rio de Janeiro, 17: 1519-9002/1679-6799, 2019. <https://revistas.ufrj.br/index. $\mathrm{php} /$ Itaca/article/view/226/215>

LAW, S. Guia ilustrado Zahar: Filosofia. Tradução Maria Luiza X. de A. Borges. 3a edição. Rio de Janeiro: Zahar, 2011.

MEYER, M. Questões de retórica: linguagem, razão e sedução. Lisboa/Portugal:

Edições 70, 2018.

NICOLA, U. Antologia ilustrada de Filosofia: das origens à idade moderna. 10a reimpressão. São Paulo: Globo (2011)

PERELMAN, C; OLBRECHTS-TYTECA, L. Tratado da argumentação: a nova retórica. Tradução de Maria Ermantina de Almeida Prado Galvão. São Paulo: Martins Fontes, 2005. 
VALLE, Bortolo. A forma do silêncio e a forma da palavra. Curitiba: Champagnat, 2003. WITTGENSTEIN, L. Tractatus logicus philosophicus. Tradução: José Arthur Giannotti. São Paulo: Cia Editora Nacional da USP, 1968. Fonte: < https://pt.slideshare.net/FernandoLima13/wittgenstein-tractatus-logico-philosophicus-portugus $>$ acesso em 03 de jul. 2020 às $14 \mathrm{~h} 35 \mathrm{~min}$.

Cultural, 1996.

Investigações Filosóficas. Tradução José Carlos Brunoi. São Paulo: Nova 